\title{
On the Nature of the Recipient Ability of Salmonella typhimurium for Foreign Deoxyribonucleic Acids
}

\author{
By MOTOYUKI OKADA AND TSUTOMU WATANABE \\ Department of Microbiology, Keio University School of Medicine, \\ Tokyo, Japan \\ AND TADASHI MIYAKE \\ Department of Molecular Biology, Keio University School of Medicine, \\ Tokyo, Japan
}

(Accepted for publication I9 July 1967)

SUMMARY

A fertile mutant (fer) isolated from Salmonella typhimurium LT-7mut with a mutator gene $m u t$ was found to have a high recipient ability when used as a recipient of the Escherichia coli chromosome and $\mathrm{F}^{\prime}$ and $\mathrm{R}$ factors, whereas LT-7mut ${ }^{+}$and $S$. typhimurium LT-2 $m u t^{+}$, both of which lack the $m u t$ gene, were poor recipients of these foreign deoxyribonucleic acids. LT-7 mut exhibited an intermediate recipient ability. These episomal elements, however, were transferred from LT-7mut and LT-7mut ${ }^{+}$to the $m u t, m u t^{+}$ and $f e r$ substrains at frequencies comparable to an $E$. coli recipient. In contrast, the frequencies of transfer of these episomes from LT-7fer to the other substrains of $S$. typhimurium were considerably lower than those to LT-7fer. The efficiencies of plating (e.o.p.) of phage P-22 grown on LT-7fer were likewise lower on LT-7mut, LT-7mut ${ }^{+}$and LT-2 $m u t^{+}$than on LT-7fer. The e.o.p. of phage P-22 on LT-7mut, LT-7mut ${ }^{+}$and LT-7mut ${ }^{+}$were increased to the value on LT-7 fer by its growth on LT-7mut $t^{+}$or LT-2 $m u t^{+}$. The frequencies of transiduction of an $\mathrm{R}$ factor to these substrains of $S$. typhimurium with phage $\mathbf{P}-22$ grown on various substrains were parallel with the e.o.p. of this phage on these strains. It was further shown that the deoxyribonucleic acid of phage $\mathrm{P}-22$, which had previously been propagated on LT-7fer, injected into LT-7mut $t^{+}$and LT-2 $m u t^{+}$is rapidly degraded, whereas appreciable breakdown did not occur in LT-7fer. These results with P-22 indicate that LT-7fer is a mutant which is impaired in its capacity of restriction and modification of this phage. The growth of P-22 on LT-7mut resulted in partial increase of its e.o.p. on LT-7mut ${ }^{+}$and LT-2 $m u t^{+}$, indicating that the restriction and modification capacities of LT- 7 mut are partially affected. The above results, that LT- 7 fer acts as a good recipient in the conjugal transfer of $E$. coli chromosome and non-viral episomes and that the frequencies of transfer of the non-viral episomes among the substrains of $S$. typhimurium are comparable to those to LT-7fer and E. coli, are interpreted as due to the restriction- and modification-less nature of $\mathrm{LT}-7 \mathrm{fer}$.

\section{INTRODUCTION}

Sexual recombination between Escherichia coli and Salmonella strains was first discovered by Baron, Carey \& Spilman (I958) and intensively studied by several groups of investigators (Baron, Carey \& Spilman, I959; Baron, Spilman \& Carey, I959; Zinder, I96io; Miyake, 1962). A characteristic feature of the mating of $E$. coli 
with salmonellas was the low recipient ability of the Salmonella strains. Baron, Carey \& Spilman (1959) succeeded by chance in isolating a good genetic recipient in a salmonella, which is capable of producing recombinants at a much higher frequency than the original strain. They were led by this finding to propose that the low frequency of recombination initially observed represented the selection of rare, high-frequency recipients from an otherwise sterile culture (Baron, Spilman \& Carey, I959). Miyake (1962) reported that in the crosses of $E$. coli Hfr strains with Salmonella typhimurium LT-7 mut, which carries a mutator gene mut (Miyake, I959; Miyake, 1960), recombinants for a range of donor markers can be produced but only at very low frequencies. Fertile recipients with a high recipient ability (LT-7fer) were isolated from LT-7 mut by indirect selection, without previous participation in recombination. Thus populations of LT-7mut were considered heterogeneous with respect to the ability to mate with $E$. coli Hfr donors (Miyake, 1962). Strains of $S$. typhimurium are usually poor recipients for the transfer of $\mathrm{R}$ factors (see Watanabe, 1963) and the sex factor $\mathrm{F}$ from $E$. coli (Watanabe, 1962). We have found that the frequencies of transfer of an $\mathrm{R}$ factor and an $\mathrm{F}^{\prime}$ factor (Jacob \& Adelberg, I959; Hirota \& Sneath, I96I) from E. coli K-I2 to LT-7fer are considerably higher than those to LT-7mut and LT-7mut ${ }^{+}$, which does not carry the mutator gene mut, and to $S$. typhimurium LT-2, that is regarded as $m u t^{+}$(Miyake, 1962). We have also found that the conjugal transfer of these episomal elements from LT-7mut, LT-7mut $t^{+}$and LT-2mut ${ }^{+}$to these strains occurs at frequencies almost equal to those to $E$. coli K-I2 and LT- $7 f e r$. These results will be reported in the present paper and the nature of fertility of the Salmonella recipients will be discussed.

\section{METHODS}

Bacterial strains. Salmonella typhimurium LT-7mut carrying the mutator gene mut and a stable mutant derived therefrom, LT- $7 m u t^{+}$without the $m u t$ gene, were employed. S. typhimurium LT-2 (originally colicin I-resistant) and its cysteine-requiring mutant cysD-36 were also used. Strain cysD-36 was supplied by H. Ozeki. Cysteine-requiring mutants isolated in our laboratory from LT-7mut, LT-7mut ${ }^{+}$and LT-7 fer, respectively, were used as well. An Hfr strain of E. coli K-I2 used was W 2252/col I (methionine requiring and colicin I-resistant, it injects its chromosome from lactose genes in a counter-clockwise direction). $\mathrm{CSH}-2 / \mathrm{col} \mathrm{I}$ (methionine-requiring and colicin I-resistant carrying an $F^{\prime}-l a c^{+}\left(\mathrm{F}_{13}\right.$ of Hirota \& Sneath, 196I), w677/PTS (requiring threonine, leucine, proline, thiamine; not fermenting mannitol, xylose, maltose, galactose, lactose; resistant to phage $\mathrm{T} 6$ and high concentrations of streptomycin, $\mathrm{F}^{-}$), and $\mathrm{w}_{3} \mathrm{IO2} / \mathrm{col} \mathrm{I}$ (non-fermenting galactose and resistant to colicin I, $\mathrm{F}^{-}$), all of which are substrains of $E$. coli $\mathrm{K}-\mathrm{I} 2$, were also used.

Phage strains. Phage P-22 (identical to PLT-22) wild type and its clear plaque mutant were employed.

Culture media and conditions of cultivation. Liquid cultures were prepared in Penassay broth (Difco) with gentle shaking. Plating media were nutrient agar (Difco), a minimal medium agar described by Davis \& Mingioli (1950) and this minimal medium agar without glucose and sodium citrate. When the utilization of lactose was the selected marker, this sugar was added in $0.2 \%$ to the minimal medium without glucose and sodium citrate (minimal lactose agar medium). Semi-solid nutrient agar medium for phage titrations contained $0.7 \%$ agar. Incubation was at $37^{\circ}$. 
Drugs. The drugs used were sulfathiazole (Takeda), dihydro-streptomycin sulfate (Takeda), chloromycetin powder (Parke, Davis \& Co.) and tetracycline hydrochloride (Lederle) and are abbreviated as $\mathrm{Su}, \mathrm{Sm}, \mathrm{Cm}$ and $\mathrm{Tc}$, respectively. The concentrations of these drugs incorporated in the media were the same as those used by Watanabe $\&$ Fukasawa (196r $a$ ); $500 \mu \mathrm{g} . / \mathrm{ml}$. for $\mathrm{Su}$ and $25 \mu \mathrm{g} . / \mathrm{ml}$. for $\mathrm{Sm}, \mathrm{Cm}$ and Tc.

Method for proving the presence of the mut gene. Whether or not the bacterial strains carry the mutator gene mut was studied by the procedure described by Treffers, Spinelli \& Belser (1954) and Miyake (I960); each colony was suspended in a small amount of saline and streaked on nutrient agar containing Sm Ioo $\mu \mathrm{g} . / \mathrm{ml}$. After overnight incubation of the plates, the streaks of the mut clones gave rise to numerous Sm-resistant colonies, whereas those of the $m u t^{+}$strains produced very few or no such colonies.

Procedure for isolating fer mutants of Salmonella typhimurium LT-7. Fertile mutants fer of $S$. typhimurium LT-7 were isolated by Miyake's printing method (I962); approximately 100 bacteria of LT-7 mut per plate were plated on nutrient agar. After overnight incubation the developed colonies were replica-plated on minimal lactose agar medium which had previously been inoculated with $0 . \mathrm{I} \mathrm{ml}$. of an overnight broth culture of $\mathrm{W} 2252 / \mathrm{col}$ I. After incubation of the replica plates for $48 \mathrm{hr}$ some of the replicaplated colonies gave heavy growth due to the lactose-fermenting $\left(\mathrm{lac}^{+}\right)$recombinants produced. Corresponding colonies on master plates were picked and retested for their high recipient ability by using the standard procedure for conjugation, described below.

Method for transduction of an $R$ factor. The method for transduction of an $\mathrm{R}$ factor 222 with phage P-22 in Salmonella typhimurium was the same as that described by Watanabe \& Fukasawa (I96I $b$ ).

Procedure for conjugation. Escherichia coli $\mathrm{K}-\mathrm{I} 2$ strain W2252/col I was used as a donor for sexual recombination. The donor and recipient strains were separately grown in Penassay broth to about $3 \times 10^{8}$ bacteria $/ \mathrm{ml}$. A I ml. portion of the donor culture was mixed with $9 \mathrm{ml}$. of a recipient culture in a $200 \mathrm{ml}$. Erlenmeyer flask and the flask incubated in a water bath for $2 \mathrm{hr}$ without agitation. Dilutions in physiological saline of this mixed culture were plated on properly enriched minimal medium to select for the recombinants. When the recipients were the substrains of Salmonella typhimurium, the donor and recipient strains were mixed in a $I: I$ or $I: 9$ ratio, and $0.1 \mathrm{ml}$. of the dilutions of the mixture was immediately plated on the selective medium (Zinder, 1960). In parallel with this procedure, the filter membrane method devised by Sanderson \& Demerec (1965) was used in some experiments. The mixture of about $3 \times 10^{8}$ donor bacteria and about $3 \times 10^{9}$ recipient bacteria was placed on a Millipore filter ( $45 \mathrm{~mm}$. diameter; HA type) by filtering the mixture of the Penassay broth cultures through the filter, and the filter with the bacteria on it was placed on the surface of a semisolid nutrient agar plate, which was then incubated for $5 \mathrm{~min}$. to permit the formation of effective cell contacts. The Millipore filter was then transferred to $10 \mathrm{ml}$. Penassay broth in a $200 \mathrm{ml}$. Erlenmeyer flask and the bacteria were gently resuspended in the broth, and the mating was allowed to proceed for $90 \mathrm{~min}$; Varying dilutions in physiological saline of this mixed culture were plated on minimal lactose agar medium. The resultant $\mathrm{lac}^{+}$recombinants were scored after incubation for $48 \mathrm{hr}$.

Procedure for transfer of an $R$ factor and an $F^{\prime}$-lac ${ }^{+}$factor. CSH-2/col I (222) was used as a donor for the transfer of the R factor 222 and $\mathrm{W} 3747 / \mathrm{col} \mathrm{I}\left(F^{\prime}-\mathrm{lac}^{+}\right)$as 
a donor for the transfer of the $F^{\prime}$-lac ${ }^{+}$. The recipients were prototrophs of Salmonella typhimurium. The donor and recipient strains were separately grown in Penassay broth to about $3 \times 10^{8}$ bacteria $/ \mathrm{ml}$. A $5 \mathrm{ml}$. portion of the donor culture was mixed with $5 \mathrm{ml}$. of recipient culture in a $200 \mathrm{ml}$. Erlenmeyer flask, and the flask was incubated in a water bath without aeration for $\mathrm{I} 6 \mathrm{hr}(\mathrm{R})$ or $3 \mathrm{hr}\left(F^{\prime}-l a c^{+}\right)$. Varying dilutions in physiological saline of the mixed culture with the $\mathrm{R}^{+}$donor were plated on minimal agar containing $\mathrm{Cm} 25 \mu \mathrm{g} . / \mathrm{ml}$. In the case of the transfer of the $\mathrm{F}^{\prime}-$ lac $^{+}$, varying dilutions in physiological saline of the mixed culture were plated on minimal lactose agar. After incubation for $48 \mathrm{br}$ the colonies of the clones which received the $\mathrm{R}$ factor or $\mathrm{F}^{\prime}-\mathrm{lac}^{+}$were scored.

Method for detection of spontaneous segregants of an $R$ factor. Spontaneous segregation of an R factor 222 and its drug resistance determinants in various substrains of Salmonella typhimurium was studied by the method described by Watanabe \& Lyang (1962); a Penassay broth culture of each substrain of $S$. typhimurium carrying 222 was diluted and plated on nutrient agars containing Sm, Cm, Tc $25 \mu \mathrm{g} . / \mathrm{ml}$. + $\mathrm{Su} 500 \mu \mathrm{g} . / \mathrm{ml}$. Two of the well-isolated colonies of each strain, which had thus been confirmed resistant to the four drugs, were used as starting materials. Five ml. of Penassay broth in a test-tube was inoculated with each colony and incubated for $24 \mathrm{hr}$ without aeration. Each culture was then diluted with fresh Penassay broth by a factor of $10^{5}$ and $0.1 \mathrm{ml}$. of this dilution transferred to $5 \mathrm{ml}$. fresh Penassay broth; subcultures were daily prepared thereafter in a similar fashion. After Io subcultures, the cultures were diluted to $1 \mathrm{O}^{-5}$ and $1 \mathrm{IO}^{-6}$, and $0 . \mathrm{I} \mathrm{ml}$. each of these dilutions was plated on drug-free nutrient agar. The patterns of drug resistance of the developed colonies were studied with a replica plating technique (Lederberg \& Lederberg, 1952).

Method for detection of colicin I production. The production of colicin I by various substrains of Salmonella tyhphimurium was studied with the method described by Fredericq (1957).

General phage techniques. The general phage techniques followed were those described by Adams (1950).

Method for study of the breakdown of the injected phage nucleic acid. ${ }^{32} \mathrm{P}-1 \mathrm{abelled}$ phage P-22 was prepared and purified by the procedure described by Watanabe $e t$ al. (I966). The method used to study the breakdown of the injected phage nucleic acid was also similar to that described by Watanabe et al. (I966).

\section{RESULTS}

Production of colicin I by various substrains of Salmonella typhimurium

Wild-type strain of LT-7 is known to produce colicin I (Ozeki, Stocker \& Smith, 1962). We have shown that LT-7mut ${ }^{+}$, LT-7mut and LT-7fer all produce the same colicin. This was shown by the finding that Escherichia coli CSH-2 but not CSH-2/col I is killed by the colicin produced by these strains. LT-2 $m u t^{+}$did not produce any detectable colicin. The production of colicin I by LT-7 necessitated the use of colicin I-resistant mutants of $E$. coli K-I2 as recipients in the crosses with LT-7 substrains.

\section{Sexual recombination between an Hfr strain W2252/col I of Escherichia coli and substrains of Salmonella typhimurium}

As shown in Table I, the frequencies of recombinants were highest in an Escherichia 
coli recipient and second highest in LT-7fer. No recombinants were found with LT-7 $\mathrm{mut}^{+}$and LT-2 $\mathrm{mut}^{+}$as recipients. LT-7mut gave intermediate frequencies of recombinants. W2252/col I injects its chromosome with the lactose genes as the leading region, and the proline genes are so closely linked to the lactose genes that they are transferred to $\mathrm{w} 677 / \mathrm{PTS}$ at almost equal frequencies.

Table I. Frequencies of recombinants in the crosses of Escherichia coli W2252/col I* with various substrains of Salmonella typhimurium

The procedure for conjugation was that of Sanderson \& Demerec (1965) which is described in the text.

Recombinants

Selected marker Frequency per donor cell

\begin{tabular}{|c|c|c|c|c|}
\hline \multicolumn{5}{|c|}{ Recipient } \\
\hline w 677/PTs $\dagger$ & LT-7 fer & LT-7 mut & LT-7 mut $t^{+}$ & LT-2 $m u t^{+}$ \\
\hline pro $^{+} \ddagger$ & $l a c^{+}+$ & $\operatorname{lac}^{+}$ & $\mathrm{lac}^{+}$ & $\mathrm{lac}^{+}$ \\
\hline $2 \cdot 0 \times 10^{-2}$ & $3.3 \times 10^{-3}$ & $1 \cdot 4 \times 10^{-5}$ & $<10^{-8}$ & $<10^{-8}$ \\
\hline
\end{tabular}

* W $2252 / \mathrm{col} \mathrm{I}$ is a methionine-requiring, colicin I-resistant Hfr strain of E. coli $\mathrm{K}-\mathrm{I} 2$.

$+\mathrm{w} 677 / \mathrm{PTS}$ is an $\mathrm{F}^{-}$substrain of $E$. coli $\mathrm{K}-12$, requiring threonine, leucine, proline and thiamin, non-fermenting mannitol, xylose, maltose, galactose and lactose, and resistant to phage T6 and high concentrations of streptomycin.

$\ddagger$ Abbreviations: pro $^{+}$non-requirement for proline; $l a c^{+}$fermentability of lactose.

\section{Transfer of an $R$ factor 222 to substrains of Salmonella typhimurium}

The mixtures of the donor and recipient cultures in Penassay broth were incubated overnight without aeration. The frequencies of transfer of an $R$ factor 222 from CSH-2/col I (222) to LT-7mut, LT-7mut and LT-2 $m u t^{+}$were very low even with overnight incubation and much lower than those to Escherichia coli $\mathrm{w}_{3} \mathrm{IO2} / \mathrm{col} \mathrm{I}$ and LT-7fer (Table 2). The filter membrane method (Sanderson \& Demerec, I965) did not improve the frequencies of $\mathbf{R}$ transfer. The frequencies of $\mathbf{R}$ transfer between the substrains of Salmonella typhimurium were rather high except with LT-7fer (222) as a donor and almost comparable to those between the substrains of $E$. coli K-I 2 . Thus, the poor recipient ability of these strains was specific for the transfer of the $\mathrm{R}$ factor from $E$. coli K-I2. LT-7fer (222) transferred its R factor at a high frequency to $E$. coli $\mathrm{K}-\mathrm{I} 2$, at a lower frequency to T-7fer and LT-2mut $t^{+}$and at even lower frequencies to LT-7mut and LT-7mut ${ }^{+}$. When LT- 7 fer was a recipient, the frequencies of transfer of the $\mathrm{R}$ factor were always high regardless of whether the donor was a substrain of $E$. coli $\mathrm{K}-\mathrm{I} 2$ or a substrain of $S$. typhimurium. Similarly, when w $3102 / \mathrm{col}$ I was a recipient, the frequencies of transfer of the $\mathrm{R}$ factor were always high regardless of whether the donor was a substrain of K-I2 or a substrain of $S$. typhimurium. The frequencies of $\mathrm{R}$ transfer from LT-2 $m u t^{+}$(222) to LT-7mut and LT-7mut $t^{+}$were slightly lower than those between the other strains of $S$. typhimurium. The frequencies shown in Table 2 cannot be taken to reflect the frequencies of transfer very accurately, because the frequencies varied to some extent from experiment to experiment.

\section{Spontaneous segregation of an $R$ factor in various substrains of Salmonella typhimurium}

The $\mathrm{Su}, \mathrm{Sm}$, and $\mathrm{Cm}$ resistance markers of the $\mathrm{R}$ factor 222 segregated at high frequencies in all of the substrains of Salmonella typhimurium. In contrast, the 
segregation of the Tc resistance marker occurred at much lower frequencies in all of these strains. These results are analogous to those reported previously by Watanabe \& Lyang (1962) with $S$. typhimurium LT-2 and there seems to be no specificity in the frequencies and patterns of segregation of the drug resistance markers of the $\mathrm{R}$ factor 222 in these substrains of $S$. typhimurium.

\section{Table 2. Frequencies of transfer of an $R$ factor $222^{*}$ among various substrains of Escherichia coli $K-I 2$ and Salmonella typhimurium}

The procedure for the transfer of the $\mathrm{R}$ factor is described in the text. The duration of mixed cultivation was $\mathrm{I} 6 \mathrm{hr}$. The values in this table represent the frequencies of $\mathrm{R}$ transfer in $\mathrm{I} \mathrm{ml}$. of the mixed cultures.

Frequency of transfer of an $\mathrm{R}$ factor 222 by the following donor

\begin{tabular}{|c|c|c|c|c|}
\hline $\begin{array}{c}\mathrm{CsH}-2 / \mathrm{col} \mathrm{I} \dagger \\
(222)\end{array}$ & $\begin{array}{l}\text { LT-7 cys } \$ \\
\text { fer }(222)\end{array}$ & $\begin{array}{l}\text { LT-7cys } \ddagger \\
\text { mut }(222)\end{array}$ & $\begin{array}{l}\text { LT- } 7 c^{c y s}{ }^{-t} \\
m u t^{+}(222)\end{array}$ & $\begin{array}{l}\mathrm{LT}-2 c y s^{-} \ddagger \\
m u t^{+}(222)\end{array}$ \\
\hline $2.6 \times 10^{6}$ & $1.0 \times 10^{7}$ & $4.0 \times 10^{6}$ & $3.0 \times 10^{6}$ & $5.0 \times 10^{6}$ \\
\hline $9.2 \times 10^{4}$ & $2 \cdot 4 \times 10^{5}$ & $3 \cdot 3 \times 10^{6}$ & $4.5 \times 10^{5}$ & $4.4 \times 10^{6}$ \\
\hline $2.0 \times 10^{1}$ & $1.9 \times 10^{4}$ & $8.5 \times 10^{5}$ & $5.6 \times 10^{5}$ & $2 \cdot 1 \times 10^{8}$ \\
\hline $4.0 \times 10^{2}$ & $9.5 \times 10^{3}$ & $1 \cdot 2 \times 10^{6}$ & $1 \cdot 3 \times 10^{6}$ & $3.2 \times 10^{3}$ \\
\hline$<10^{1}$ & $1 \cdot 2 \times 10^{5}$ & $5.6 \times 10^{5}$ & $3.8 \times 10^{6}$ & $3.5 \times 10^{4}$ \\
\hline
\end{tabular}

* $\mathrm{R}$ factor 222 carries the markers of resistance to sulphonamides, streptomycin, chloramphenicol and tetracycline.

$\dagger \mathrm{CSH}-2 / \mathrm{col} \mathrm{I}$ is an $\mathrm{F}^{-}$, methionine-requiring, colicin I-resistant substrain of $E$. coli $\mathrm{K}-\mathrm{I} 2$.

$\$$ cys $^{-}$stands for cysteine-requirement. LT-2 cys ${ }^{-}$mut $t^{+}$is identical to cysD-36.

$\S \mathrm{W} 3 \mathrm{IO} / \mathrm{col} \mathrm{I}$ is an $\mathrm{F}^{-}$, galactose-non-fermenting, colicin I-resistant substrain of $E$. coli K-I2.

Table 3. Frequencies of transduction of an $R$ factor $222 *$ to various substrains of Salmonella typhimurium with phage $P-22$

The procedure for transduction of the $\mathrm{R}$ factor is the same as that described by Watanabe \& Fukasawa (196I $b$ )

Frequency of chloramphenicol-resistant transductants per donor phage with the following donor

\begin{tabular}{|c|c|c|c|c|}
\hline Recipient & LT-7fer (222) & LT-7 mut (222) & LT-7mut $t^{+}(222)$ & LT-2 $m u t^{+}(222)$ \\
\hline LT-7fer & $1.7 \times 10^{-8}$ & $2.2 \times 10^{-8}$ & $9.0 \times 10^{-8}$ & $\mathrm{I} \cdot 2 \times 1 \mathrm{IO}^{-7}$ \\
\hline $\mathbf{L T}-7 m u t$ & $<4.8 \times 10^{-10}$ & $8.0 \times 10^{-10}$ & $1.6 \times 10^{-8}$ & $7 \cdot 1 \times 10^{-8}$ \\
\hline LT-7 mut $^{+}$ & $<4.8 \times 10^{-10}$ & $8.0 \times 10^{-10}$ & $1 \cdot 7 \times 10^{-7}$ & $1 \cdot 8 \times \mathrm{IO}^{-7}$ \\
\hline LT-2 mut $^{+}$ & $<4.8 \times 10^{-10}$ & $4.0 \times 10^{-10}$ & $4.0 \times 10^{-7}$ & $2.5 \times 10^{-7}$ \\
\hline
\end{tabular}

* $\mathrm{R}$ factor 222 carries the markers of resistance to sulphonamides, streptomycin, chloramphenicol and tetracycline.

\section{Transduction with phage $P-22$ of an $R$ factor 222 in various substrains of Salmonella typhimurium}

The frequencies of transduction of an $\mathrm{R}$ factor 222 with phage P-22 grown on LT-7mut $t^{+}$or LT-2 $m u t^{+}$carrying the R factor 222 to various substrains of Salmonella typhimurium were about equal as seen in Table 3 . In contrast, the frequencies of transduction of the $\mathrm{R}$ factor 222 with P-22 grown on LT-7fer (222) were about $10^{-8}$ per infective phage in LT-7fer but much lower in LT-7mut, LT-7mut $t^{+}$and LT-2mut $t^{+}$ (less than $4.8 \times 10^{-10}$; Table 3 ). The phage grown on LT-7mut (222) gave a similar but less pronounced tendency of transduction to the phage grown on LT-7fer. 


\section{Frequencies of transfer of an $F^{\prime}$-lac ${ }^{+}$to various substrains of}

\section{Salmonella typhimurium}

The mixtures of the donor and recipient cultures in Penassay broth were incubated for $3 \mathrm{hr}$ without aeration. The frequencies of transfer of the $\mathrm{F}^{\prime}-\mathrm{lac}^{+}$to various substrains of Salmonella typhimurium from w $3747 / \mathrm{col} \mathrm{I}\left(\mathrm{F}^{\prime}-\mathrm{lac}^{+}\right)$and various substrains of $S$. typhimurium carrying the $\mathrm{F}^{\prime}-\mathrm{lac}^{+}$are shown in Table 4. The frequencies of $l a c^{-}$ bacteria were scored on each donor culture for the transfer experiments, because the frequencies of spontaneous segregation of the $\mathrm{F}^{\prime}-l a c^{+}$were rather high in Salmonella strains. As seen in Table 4 , the frequencies of transfer of the $\mathrm{F}^{\prime}$-lac to LT- 7 fer were higher than those to the other substrains of $S$. typhimurium when the donor was a substrain of $\mathrm{K}-\mathrm{I} 2$. The same tendency was observed also with LT-7fer $\left(\mathrm{F}^{\prime}-l a c^{+}\right)$as a donor. In contrast, the frequencies of transfer of the $F^{\prime}-l a c^{+}$from LT-7mut, LT-7mut ${ }^{+}$ and LT-2 $m u t^{+}$did not show marked differences among the various recipients (Table 4 ). These data gave some fluctuations in several independent experiments.

\section{Table 4. Frequencies of transfer of an $F^{\prime}-l a c^{+*}$ among Escherichia coli $K-I 2$ and various substrains of Salmonella typhimurium}

The procedure for studying the frequencies of transfer of the $F^{\prime}-l a c^{+}$is described in the text. The duration of mixed cultivation was $3 \mathrm{hr}$ in this experiment. The spontaneous segregants without $\mathrm{F}^{\prime}$-lac ${ }^{+}$were determined on each donor in the transfer experiments and were found to range between o and $60 \%$; LT-7 $\mathrm{cys}^{-}$fer $0 \%$, LT-7 $\mathrm{cys}^{-} \mathrm{mut}^{50} \%$, LT-7 $\mathrm{cys}^{-} \mathrm{mut}^{+}$ $60 \%$, and $\mathrm{LT}-2 \mathrm{cys}^{-} \mathrm{mut}^{+} 50 \%$. The values in this table show the frequencies of $\mathrm{F}^{\prime}$ transfer in $\mathrm{I} \mathrm{ml}$. of the mixed cultures of the donor and the recipient.

Frequency of transfer of an $F^{\prime}$-lac $c^{+}$by the following donor

\begin{tabular}{|c|c|c|c|c|c|}
\hline Recipient & $\begin{array}{c}\text { W } 3747 / \text { col I } \dagger \\
\left(F^{\prime}-l a c^{+}\right)\end{array}$ & $\begin{array}{l}\text { LT-7 cys }-f e r \\
\left(F^{\prime}-l a c^{+}\right)\end{array}$ & $\begin{array}{l}\text { LT-7cys mut } \\
\quad\left(F^{\prime}-l a c^{+}\right)\end{array}$ & $\begin{array}{c}\mathrm{LT}-7 c y s^{-} m u t^{+} \\
\left(F^{\prime}-l a c^{+}\right)\end{array}$ & $\begin{array}{c}\mathrm{LT}-2 c^{c y s^{-}} m u t^{+} \\
\left(F^{\prime}-l a c^{+}\right)\end{array}$ \\
\hline LT-7fer & $6.0 \times 10^{6}$ & $2.0 \times 10^{6}$ & $2 \cdot 2 \times 10^{4}$ & $4.0 \times 10^{4}$ & $2.0 \times 10^{5}$ \\
\hline LT-7 mut & $4.7 \times 10^{4}$ & $2.8 \times 10^{4}$ & $4.4 \times 10^{3}$ & $7.8 \times 10^{3}$ & $\mathrm{I} \cdot 2 \times 10^{5}$ \\
\hline LT-7mut ${ }^{+}$ & $3.7 \times 10^{4}$ & $9.5 \times 10^{3}$ & $2 \cdot 1 \times 10^{3}$ & $5.0 \times 10^{3}$ & $1.5 \times 10^{5}$ \\
\hline LT- $2 m u t^{+}$ & $2 \cdot 1 \times 10^{2}$ & $\mathrm{I} \cdot 8 \times 10^{5}$ & $3.5 \times 10^{3}$ & $3.5 \times 10^{3}$ & $2 \cdot 1 \times 10^{5}$ \\
\hline
\end{tabular}

* $F^{\prime}$-lac ${ }^{+}$is $\mathrm{F}_{13}$ of Hirota \& Sneath (I96I).

$\dagger \mathrm{w} 3747 / \mathrm{col} \mathrm{I}$ is an $\mathrm{F}^{-}$, methionine-requiring, colicin I-resistant mutant of E. coli $\mathrm{K}-\mathrm{I} 2$.

+ LT-2 cys $^{-}$mut $^{+}$is identical to cysD-36.

\section{Efficiencies of plating (e.o.p.) of phage P-22 on various substrains of Salmonella typhimurium}

It was previously noted by Miyake (1962) that phage grown on LT-7fer gave a high e.o.p. on LT-7fer, a lower e.o.p. on LT-7mut and an even lower e.o.p. on LT-7mut ${ }^{+}$. The adsorption of this phage took place equally well to these strains. We have shown that a clear mutant of this phage gives an e.o.p. on LT-2mut $t^{+}$as low as on LT-7mut ${ }^{+}$ (Table 5). The e.o.p. of this mutant phage on LT-7mut, LT-7mut ${ }^{+}$and LT-2mut $t^{+}$were found to be increased by its growth on any of these bacterial strains. The e.o.p. on LT-7mut, LT-7mut ${ }^{+}$and LT-2mut $t^{+}$of the phage grown on LT-7mut $t^{+}$or LT-2 $m u t^{+}$ were equal to those on LT-7fer, whereas the phage grown on LT-7 mut gave slightly lower e.o.p. on LT-7mut, LT-7mut $t^{+}$and LT-2 $m u t^{+}$than on LT-7jer.

We made single-plaque isolations from the plaques developed on LT-2 $m u t^{+}$plated 
with phage P-22 which had previously grown on LT-7fer. A broth suspension of each purified plaque was prepared and LT-2 $m u t^{+}$was infected with it. All the lysates thus obtained gave equal e.o.p. on every substrain of Salmonella typhimurium. Conversely, the propagation on LT- 7 fer of phage P-22 which had previously grown on LT-2 $\mathrm{mut}^{+}$ resulted in the reduction of e.o.p. on LT-7mut, LT-7mut $t^{+}$and LT-2mut $t^{+}$.

Table 5. Efficiencies of plating of a clear mutant of phage P-22 on various substrains of Salmonella typhimurium

Efficiency of plating of phage P-22 grown on:

\begin{tabular}{|c|c|c|c|c|}
\hline \multirow[b]{2}{*}{ Indicator } & \\
\hline & LT-7fer & LT-7 mut & LT-7 mut ${ }^{+}$ & LT-2 $m u t^{+}$ \\
\hline LT-7fer & $I \cdot O$ & $I \cdot O$ & $I \cdot O$ & $1 \cdot 0$ \\
\hline LT-7mut & $1.0 \times 10^{-4}$ & $4.0 \times 10^{-1}$ & $8.6 \times 10^{-1}$ & $2 \cdot I$ \\
\hline LT- $7 \mathrm{mut}^{+}$ & $3.0 \times 10^{-5}$ & $\mathrm{I} \cdot 3 \times 10^{-2}$ & $8.3 \times 10^{-1}$ & $1 \cdot 4$ \\
\hline LT-2 mut ${ }^{+}$ & $6.0 \times 10^{-5}$ & $2.0 \times 10^{-2}$ & $\mathrm{I} \cdot 2$ & $I \cdot 4$ \\
\hline
\end{tabular}

Since LT-7mut cultures are heterogeneous, containing fertile and infertile cells as was pointed out above, the results of the e.o.p. of the phage propagated on LT-7mut on the other indicators might be due to the heterogeneous population of the phage, some phage particles being propagated on the fertile cells and other phage particles on the infertile cells. The following single burst experiments were carried out to test this possibility.

\section{Single burst experiments with a clear mutant of phage P-22 in Salmonella typhimurium LT-7 mut}

A culture of LT-7mut containing $8.4 \times 10^{2}$ bacteria $/ \mathrm{ml}$. was infected with a clear mutant of phage P-22 propagated on LT-7mut at a multiplicity of input of 4. The infected culture was diluted with Penassay broth so that $\mathrm{I} \mathrm{ml}$. contained 0.3 infected bacterium and distributed in 50 small test-tubes in a volume of $1 \mathrm{ml}$. in each tube. The content of each tube, after incubation for $2 \mathrm{hr}$, was divided into two equal portions and was separately plated for phage titrations with LT- 7 fer and LT- $7 \mathrm{mut}^{+}$, respectively, as indicators. All of the $\mathrm{I} 3$ samples which gave bursts yielded consistently higher titres on LT-7 fer than on LT-7mut $t^{+}$, the ratio between them being about 3:I. Similar results were obtained in several other independent experiments. These results suggest that the low e.o.p. on LT-7mut $t^{+}$of the phage grown on LT-7mut is probably not due to its growth on the heterogeneous population of LT- 7 mut.

\section{Isotope studies on the fate of the injected phage nucleic acid}

It was found that $30-40 \%$ of the deoxyribonucleic acid (DNA) of a clear-plaque mutant of phage P-22, which had previously been propagated on LT-7 fer, was degraded to acid soluble fractions in 10 min. in LT-7mut ${ }^{+}$and LT-2 $m u t^{+}$, whereas less than $10 \%$ of the ${ }^{32} \mathrm{P}$ label of the phage DNA became acid-soluble in LT-7fer in $10 \mathrm{~min}$. In contrast, less than $10 \%$ of the DNA of the clear mutant of P-22, which had previously grown on LT- $2 m u t^{+}$, was degraded to acid-soluble fractions in Io min. in any of the strains LT-7fer, LT-7mut $t^{+}$and LT-2 $m u t^{+}$. 


\section{DISCUSSION}

As reported in the present paper, the conjugal transfer of $F^{\prime}$ and $\mathrm{R}$ factors occurred most frequently to LT-7fer among various substrains of Salmonella typhimurium. We have also confirmed with an Hfr strain a previous finding of Miyake (1962) that LT-7 fer has a high recipient ability in the crosses with different Hfr strains of Escherichia coli $\mathrm{K}-\mathrm{I}$ 2. Thus LT-7fer acts as an unusually good recipient among the substrains of $S$. typhimurium in the conjugal transfer of bacterial chromosomes and episomal elements.

We have shown that phage P-22 grown on LT-7fer gives a very much reduced e.o.p. on any other derivatives of Salmonella tyhphimurium, namely LT-7mut, LT-7mut ${ }^{+}$ and LT-2 $m u t^{+}$. Phage P-22 grown on LT-7mut ${ }^{+}$or LT-2mut ${ }^{+}$, however, gave almost equal e.o.p. on any of the substrains of $S$. typhimurium. In contrast, the phage propagated on LT-7mut gave slightly lower e.o.p. on LT-7mut, LT-7mut ${ }^{+}$and LT-2mut $t^{+}$ than on LT-7fer. We have further shown that the DNA of a clear-plaque mutant of phage P-22, which had previously been propagated on LT-7fer, is rapidly degraded after its injection into LT-7mut ${ }^{+}$and LT-2 $m u t^{+}$, whereas appreciable breakdown did not occur in LT-7fer. On the contrary, the DNA of the clear mutant of P-22, which had previously grown on LT-2 $\mathrm{mut}^{+}$, was not degraded appreciably in any of the substrains of $S$. typhimurium. These results indicate that the observed phenomena are due to host-controlled restriction and modification as defined by Arber \& Dussoix (1962) and Arber (1965). They may be interpreted in the following two alternative ways: (I) that LT-7fer is a mutant which lacks the capacity of host-controlled restriction and modification; (2) that LT-7mut $t^{+}$and LT-2 $m u t^{+}$lack the capacity of modification, whereas LT-7fer and LT-7mut are possessed of this capacity. In other words, it can be said that P-22 is modified by growth on LT-7fer or LT-7mut so that it will be restricted in LT-7mut ${ }^{+}$and LT-2 $m u t^{+}$. Thus phage P-22 acquires new host specificity (Arber \& Dussoix, 1962) by growth on LT-7fer and will be restricted in LT-7mut, LT-7mut $t^{+}$and LT-2mut ${ }^{+}$. The fact that P-22 grown on LT-7fer is still restricted on LT-7 mut indicates that modifications of P-22 by LT-7 fer and LT-7 mut may be different. It should be pointed out that LT-7fer is regarded as restriction-less in either interpretation. The first interpretation seems more reasonable, since it is known that restriction and modification are usually impaired together (Arber \& Morse, I965; Boyer, 1964; Wood, 1966).

The results of transduction with phage P-22 of host chromosomal markers reported previously by Miyake (1962) and of an R factor reported in the present paper with various substrains of Salmonella tyhpimurium as recipients are also compatible with these interpretations, since the frequencies of transduction with P-22 grown on LT-7fer or LT-7mut were considerably higher to LT-7fer than to the other strains. In contrast, the phage grown on LT- $7 m u t^{+}$or LT- $2 m u t^{+}$transduced the $\mathrm{R}$ factor to various substrains at almost equal frequencies. Spontaneous segregation of an $R$ factor or its drug-resistance markers occurred equally frequently in various substrains of $S$. typhimurium, indicating that the $\mathrm{R}$ factor replicates equally well in the various substrains, once it has started replication.

It has been found in several systems of host-controlled restriction and modification that a wide variety of foreign DNA are restricted and modified in common, including phage genomes, non-viral episomes and bacterial chromosomes (Arber, I964; Arber, 
1965; Arber \& Morse, 1965; Boice \& Luria, 1963; Pittard, 1964; Watanabe et al. 1964; Watanabe et al., 1966). Our finding that LT-7fer acts as a good recipient for bacterial chromosomes and $\mathrm{F}^{\prime}$ and $\mathrm{R}$ factors can be easily understood, if the restriction and modification are exerted in common upon these foreign DNA. In fact, as we will report in a following paper, we have been able to show that a number of mutants of LT-2 with high recipient abilities selected by the transfer of an R factor from Escherichia coli $\mathrm{CSH}-2$ (222) behaved, after elimination of the $\mathrm{R}$ factor with acridine dyes, as good recipients of K-12 chromosomes. Furthermore, phage P-22 grown on any substrains of LT-2 and LT-7 gave highest e.o.p. on these mutants. These results seem to suggest that the aforementioned pleiotropic phenomena are caused by single genetic events.

If we adopt the first interpretation as to the modification of phage P-22, its modification is complete on LT-7mut $t^{+}$and LT-2 $m u t^{+}$in view of the e.o.p. on the substrains of Salmonella typhimurium of the phage propagated on these strains. The modification of $\mathrm{F}^{\prime}$ and $\mathrm{R}$ factors, however, did not give clear-cut results. As the results in Table 4 indicate, the frequencies of transfer of an $\mathrm{F}^{\prime}$ from LT- $7 m u t^{+}\left(F^{\prime}-l a c^{+}\right)$to LT-7mut, LT-7 $\mathrm{mut}^{+}$and LT-2 $\mathrm{mut}^{+}$were considerably lower than those to LT-7fer, whereas the frequencies of transfer of the $\mathrm{F}^{\prime}$ from LT-2 $\mathrm{mut}^{+}\left(\mathrm{F}^{\prime}-\mathrm{lac}^{+}\right)$to those strains were almost equal. On the other hand, the frequencies of transfer of the R factor 222 from LT-2mut (222) to LT-7mut, LT-7mut ${ }^{+}$were much lower than that to LT-7fer, whereas the frequencies of R transfer from LT- $7 \mathrm{mut}^{+}$(222) to various substrains of $S$.typhimurium were almost equal (Table 2). These results are not completely parallel with the results of the e.o.p. of phage P-22 on the substrains of S. typhimurium. This discrepancy may be at least partly due to the experimental conditions we used: we incubated the mixtures of the donor and recipient cultures overnight or for $3 \mathrm{hr}$, because the frequencies of transfer of $R$ and $F^{\prime}$ factors were too low in some recipients to detect in the ordinary $\mathrm{I} \mathrm{hr}$ incubation. The incubation for long durations may have caused some distortion of the frequencies of transfer of these episomes. Some other unknown factors might also be involved.

Eisenstark (1965) succeeded in isolating fertile mutants from LT-2 $m u t^{+}$through treatment with a mutagen, nitrosoguanidine; Miyake (1962) had presented some evidence that such mutations may occur in LT-2 $m u t^{+}$spontaneously. These results are compatible with our results and hypothesis that fertility is given by the restrictionless mutation. The fact that fertile mutants are easily isolated in LT-7mut is considered to be merely because this strain is a mutable one due to the presence of the mutator gene.

The hybrids between Escherichia coli and Salmonella exhibit a high recipient ability when used as recipients in the crosses with $E$. coli donors (Baron, Carey \& Spilman, 1959; Miyake, 1962). This finding was interpreted as due to the selection of high-frequency recipients and this fits well our data and hypothesis. Johnson, Falkow \& Baron (1964), however, later demonstrated that the increased recipient ability of the hybrids of $E$. coli and $S$. typhi is due to the presence of integrated $E$. coli genetic material. They further showed that the recipient ability of these hybrids was increased only when their substituted $E$. coli genetic section matched the leading region of the Hfr chromosome. They also mentioned that the Salmonella population is probably homogeneous with respect to its initial ability to mate with $E$. coli on the basis of the finding that the transfer of an $F^{\prime}-l a c^{+}$element occurred only 
slightly less efficiently from an $E$. coli $\mathrm{F}^{\prime}$ donor to Salmonella than it did to an $E$. coli $\mathrm{F}^{-}$recipient. In contrast, in our results, the transfer of an $\mathrm{F}^{\prime}$ from $E$. coli to the substrains of $S$. typhimurium except to LT- 7 fer occurred at much lower frequencies than to $E$. coli recipients. The discrepancies between the results of Johnson et al. (I964) and ours may probably be due to the difference in the strains employed; Johnson et al. (1964) employed $S$. typhi, whereas we used $S$. typhimurium.

This investigation was supported in part by U.S. Public Health Service research grant AI-04740 from the National Institute of Allergy and Infectious Diseases.

\section{REFERENCES}

AdAMs, M. H. (I950). Methods of study of bacterial viruses. Meth. med. Res. 2, I.

ARBER, W. (1964). Host specificity of DNA produced by Escherichia coli. III. Effects on transduction mediated by $\lambda d g$. Virology $23, \mathrm{I} 73$.

Arber, W. (1965). Host-controlled modification of bacteriophage. A. Rev. Microbiol. 19, 365.

ARber, W. \& Dussoix, D. (1962). Host specificity of DNA produced by Escherichia coli. I. Host controlled modification of bacteriophage $\lambda . J$. molec. Biol. 5, I 8.

ARBER, W. \& MORSE, M. L. (I965). Host specificity of DNA produced by Escherichia coli. VI. Effects on bacterial conjugation. Genetics 5I, I37.

Baron, L. S., Carey, W. F. \& Spilman, W. M. (I958). Hybridization of Salmonella species by mating with Escherichia coli. Int. Congr. Microbiol., Stockholm, p. 50.

Baron, L. S., Carey, W. F. \& SpIlman, W. M. (I959). Genetic recombination between Escherichia coli and Salmonella typhimurium. Proc. natn. Acad. Sci. U.S.A. 45, 976.

Baron, L. S., SpIlman, W. M. \& Carey, W. F. (1959). Hybridization of Salmonella species by mating with Escherichia coli. Science, N.Y. 130, 566.

BoIce, L. B. \& LuRIA, S. E. (I963). Behavior of prophage PI in bacterial matings. I. Transfer of the defective prophage P I dl. Virology 20, I47.

BOYer, H. (1964). Genetic control of restriction and modification in Escherichia coli. J. Bact. 87, 1652 .

Davis, B. D. \& Mingioli, E. S. (I950). Mutants of Escherichia coli requiring methionine or vitamin $\mathrm{B}_{12}$. J. Bact. 60, 17 .

EISENSTARK, A. (1965). Mutagen-induced hybridization of Salmonella typhimurium LT-2 $\times$ Escherichia coli $\mathrm{K} \mathrm{I} 2 \mathrm{Hfr}$. Proc. natn. Acad. Sci., U.S.A. 54, I I 7.

FredericQ, P. (1957). Colicins. A. Rev. Microbiol. II, 7.

Hirota, Y. \& SNeAth, P. H. A. (1961). $\mathrm{F}^{\prime}$ and F mediated transduction in Escherichia coli K-1 2. Japan. J. Genetics 36, 307.

JACOB, F. \& AdelBerg, E. A. (1959). Transfert de caractères génétique par incorporation au facteur sexual d'Escherichia coli. C. r. hebd. Séanc., Acad. Sci., Paris 249, 189.

Johnson, E. M., FALkow, S. \& BARON, L. S. (1964). Recipient ability of Salmonella typhosa in genetic crosses with Escherichia coli. J. Bact. 87, 54.

Lederberg, J. \& Lederberg, E. M. (1952). Replica plating and indirect selection of bacterial mutants. J. Bact. 63, 399.

MiYAKe, T. (1959). Fertility factor in Salmonella typhimurium. Nature, Lond. 184, 657.

MiYAKe, T. (I960). Mutator factor in Salmonella typhimurium. Genetics 45, I I.

MrYAKE, T. (1962). Exchange of genetic material between Salmonella typhimurium and Escherichia coli $\mathrm{K}-12$. Genetics 47, 1043 .

Ozeki, H., Stocker, B. A. D. \& SMIth, S. M. (I962). Transmission of colicinogeny between strains of Salmonella typhimurium grown together. J. gen. Microbiol. 28, 67I.

PitTARD, J. (I964). Effect of phage controlled restriction on genetic linkage in bacterial crosses. J. Bact. 87, 1256.

Sanderson, K. E. \& Demerec, M. (1965). The linkage map of Salmonella typhimurium. Genetics 5I, 897. 
Treffers, H. P., Spinelli, V. \& Belser, N. D. (1954). A factor (or mutator gene) influencing mutation rates in Escherichia coli. Proc. natn. Acad. Sci., U.S.A. 40, I064.

WatANABE, T. (1962). Episomic resistance factors in Enterobacteriaceae. XVII. Further studies on the transduction of resistance factors in Salmonella typhimurium. Med. Biol., Tokyo 65, 44 .

WataNABE, T. (1963). Infective heredity of multiple drug resistance in bacteria. Bact. Rev. $27,87$.

Watanabe, T. \& FuKasawa, T. (I96I $a$ ). Episome-mediated transfer of drug resistance in Enterobacteriaceae. I. Transfer of resistance factors by conjugation. J. Bact. 81, 669 .

Watanabe, T. \& Fukasawa, T. (196I $b$ ). Episome-mediated transfer of drug resistance in Enterobacteriaceae. III. Transduction of resistance factors. J. Bact. 82, 202.

Watanabe, T. \& Lyang, K. W. (1962). Episome-mediated transfer of drug resistance in Enterobacteriaceae. V. Spontaneous segregation and recombination of resistance factors in Salmonella typhimurium. J. Bact. 84, 422.

Watanabe, T., Nishida, H., Ogata, C., Arai, T. \& Sato, S. (I964). Episome-mediated transfer of drug resistance in Enterobacteriaceae. VII. Two types of naturally occurring R factors. $J$. Bact. 88, 716.

Watanabe, T., Takano, T., Arai, T., Nishida, H. \& Sato, S. (I966). Episome-mediated transfer of drug resistance in Enterobacteriaceae. X. Restriction and modification of phages by $f^{-} \mathrm{R}$ factors. J. Bact. $92,477$.

Wood, W. B. (I966). Host specificity of DNA produced by Escherichia coli: Bacterial mutations affecting the restriction and modification of DNA.J. molec. Biol. 16, 118.

ZINDER, N. D. (1960). Hybrids of Escherichia and Salmonella. Science, N.Y. 13I, 8I3. 